\title{
Reseña de Cities in global capitalism
}

\author{
Review of Cities in global capitalism
}

\author{
Luis Alfonso Escudero Gómez $z^{1}$ (b)
}
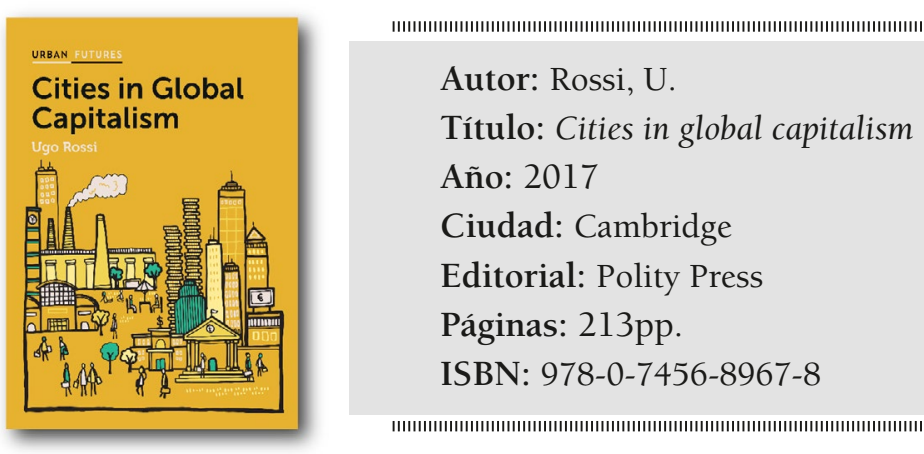

Autor: Rossi, U.

Título: Cities in global capitalism

Año: 2017

Ciudad: Cambridge

Editorial: Polity Press

Páginas: 213pp.

ISBN: 978-0-7456-8967-8

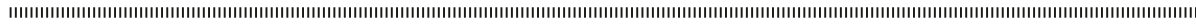

El geógrafo italiano, de origen napolitano, Ugo Rossi ha publicado una monografía sobre las ciudades en el capitalismo global en la editorial Polity Press. Tras una brillante labor investigadora, con múltiples artículos en revistas científicas de prestigio, y docente, con estancias en diferentes universidades europeas, desarrollando su labor principal en la de Turín, y estadounidenses, Rossi ha elaborado una magna obra teórica de Geografía Urbana. De hecho, una primera circunstancia que llama la atención es el exclusivo carácter teórico del libro, dado que no hay ni una sola figura o tabla ni tampoco la más mínima cartografía.

El autor se basa en las referencias académicas comunes en los últimos estudios internacionales sobre la ciudad: Aalbers, Brenner, Castells, Florida, Hall, Harvey, Lefebvre, Marcuse, Sassen, Smith, Zukin, etc. Además, no duda en recurrir a diferentes pensadores clave desde Foucault a Marx, incluyendo a Deleuze, Giddens, Jameson, Weber, Zizek y un largo etcétera. Finalmente, también utiliza autores procedentes de la literatura científica italiana: Arrighi, Esposito, Lazzarato, Marazzi o Vanolo, entro otros muchos.
Con este amplio bagaje bibliográfico previo, Rossi es capaz de construir una visión original sobre la ciudad en el presente, incluida su evolución tras lo que él denomina la «Gran Depresión», la crisis económico-financiera global de 2008. La tesis principal es que el urbanismo neoliberal o el neoliberalismo urbano definen la condición actual de la ciudad, una urbe contemporánea capitalista. El autor defiende que con el advenimiento de la globalización neoliberal se ha producido una generalización de la ciudad capitalista como la forma socioespacial dominante en el planeta. Y, en este sentido, la urbanización y el urbanismo son componentes esenciales del proceso capitalista.

Esta tesis principal va a ser desarrollada por Rossi en cinco grandes capítulos que reciben los sintéticos e imaginativos nombres de, sucesivamente, «Emergencias», «Extensiones», «Continuidades», «Difusiones» y «Variaciones». El propio autor explica que cada capítulo es ilustrativo de una dinámica social específica a través de la cual las ciudades se enredan en el capitalismo global. El primero identifica tres emergencias dentro de la relación ciudadcapitalismo a largo plazo: el poder financiero, el

1 Departamento de Geografía y Ordenación del Territorio, Universidad de Castilla-La Mancha, España. luisalfonso.escudero@uclm.es 
emprendimiento y el capital cognitivo. El segundo analiza el primer componente de la globalización neoliberal: lo global y, en concreto, la relación entre las ciudades y la globalización. El tercero está dedicado a estudiar el segundo componente de la globalización neoliberal: el neoliberalismo y su relación de inmanencia con la ciudad capitalista. El cuarto se centra en los procesos de homogeneización resultantes de los fenómenos globales de la colonización capitalista. El quinto está dedicado al análisis de las variaciones de las condiciones globales del dominio neoliberal. Finalmente, tras recapitular los principales argumentos de los capítulos previos, el libro concluye con una reflexión sobre la ambivalencia de la condición urbana en el contexto actual de turbulencia generalizada que afecta al capitalismo global y sobre sus riesgos.

Resulta difícil sintetizar 180 páginas de escrito teórico sobre la ciudad hoy en unas pocas líneas. Por esta razón, se prefiere escoger unas ideas significativas. Es el resultado, no obstante, de una selección subjetiva del autor de esta reflexión sobre la obra de Rossi. Otro lector podría elaborar una reseña totalmente diferente, dada la riqueza de argumentos e ideas que aparecen en el libro.

Una de las sólidas premisas que destacamos en el análisis de la ciudad en el capitalismo global de Rossi es que determinadas funciones centrales de la urbe actual son desempeñadas por fuerzas tan diferentes como la financiarización, la capacidad institucional, el espíritu empresarial innovador, el sector de la vivienda, el consumo, la tecnología y la economía cultural. Aunque pueden considerarse entidades autónomas, el autor demuestra que estos factores también están interrelacionados. Por ejemplo, la financiarización convierte a los residentes de la ciudad simultáneamente en entidades explotadas, sobreendeudadas, principalmente por la vivienda y el consumo, y en sujetos potencialmente emprendedores.

Por otro lado, la generalización del urbanismo neoliberal y la propagación de elementos urbanos comunes provoca interesantes procesos, como demuestra Rossi. Así, hoy todas las ciudades aspiran a ser más inteligentes y creativas, sostenibles y resilientes. Igualmente, las urbes contemporáneas, de manera casi uniforme, han pretendido explotar el consumo y el potencial de entretenimiento involucrando una amplia gama de entornos urbanos, como frentes de agua, centros históricos, áreas ex industriales y, más notablemente, barrios neobohemios (por supuesto, Rossi explica la cuestión de la gentrificación en las páginas del libro). Otro posicionamiento común y extendido en el presente, tras la crisis de 2008, es la forma de un «estado de excepción» normalizado en el que las desposesiones se han convertido en la norma de las relaciones sociales dentro de regímenes urbanos impulsados por la austeridad.

Una interesante idea y conclusión que se extiende transversalmente por todo el libro, y que el autor defiende como uno de sus argumentos propios principales, es la de la empresarialización (entrepreneurialization en inglés) neoliberal de la sociedad en las ciudades actuales; en el sentido de que en el presente se espera que todos obtengamos ganancias de nuestras posesiones de forma emprendedora. Es el resultado de una economía basada en la tecnología que ha impulsado la tendencia del capitalismo a mercantilizar la vida como un todo, creando nuevas formas de explotación y autoexplotación.

Rossi se refiere, en concreto, al fenómeno de la economía colaborativa (sharing economy) basada en la tecnología, que tras la crisis de 2008 ha experimentado un crecimiento vertiginoso dentro de los sectores de consumo típicamente asociados con los entornos urbanos como la vivienda, el transporte, la alimentación y la educación. Para el autor no resulta sorprendente que el fenómeno de la economía colaborativa haya estallado en los años posteriores a la recesión. Las compañías pioneras como Airbnb y Uber se fundaron en 2008 y 2009, respectivamente, pero ganaron popularidad después del final de la recesión en los Estados Unidos.

Estas actividades económicas pretenden ofrecer oportunidades de ingresos suplementarios a una clase media empobrecida tras la crisis. Así, la gente común se reinventa a sí misma como emprendedora a tiempo parcial a través de su participación en la economía colaborativa basada en la tecnología. El autor señala que el consumo tecnológico es particularmente adecuado para un capitalismo de 24 horas los siete días de la semana, en el que se requiere que todos sean implacablemente activos y productivos, siempre y en todas partes, en constante conexión con el mundo exterior a través de dispositivos tecnológicos «inteligentes».

Esta mercantilización de la vida urbana y la extensión y dominio planetario del urbanismo neoliberal y del capitalismo global de mercado no pueden esconder, sin embargo, las injusticias de la condición urbana global en un contexto de dominio neoliberal. Aunque hayan tenido lugar importantes movimientos sociales de protesta y solidaridad ante esta situación tras la crisis de 
2008, Rossi también se muestra preocupado por fenómenos contrarios como la posibilidad siempre presente del fascismo, recordemos nuevamente el origen italiano del autor, entre una clase media cada vez más frustrada; además de la señalada empresarialización y mercantilización de la vida urbana donde cada ciudadano es consumidor y empresario. La magia del neoliberalismo sería convertirnos a todos en neoliberales, es decir, el riesgo de ser absorbido por la corriente principal del discurso capitalista.

En esta disyuntiva nos encontramos en el presente en las ciudades, entre la resurrección de la solidaridad urbana en las relaciones sociales mediante los movimientos orientados a los bienes comunes y el riesgo de un dominio neoliberal global, no solo ya en las ciudades, donde es un hecho, sino también en sus ciudadanos. En esta situación, Rossi apela a una repolitización emancipadora de la vida urbana. Para él, esto sería esencial con el fin de descubrir y poner en evidencia la ambivalencia y las injusticias de la condición urbana global en un contexto de dominio neoliberal.

En definitiva, estamos ante un libro que nos ayuda a entender la ciudad hoy, dentro de un capitalismo neoliberal global. Una monografía con múltiples claves interpretativas, basada en sólidos fundamentos teóricos y con aportaciones originales del autor. La obra puede dar lugar a una reflexión cómo la que se ha hecho en las líneas anteriores, o a otras fundamentadas en otros argumentos presentes en el libro. También su lectura invita al acuerdo y/o al desacuerdo de muchos de los argumentos desarrollados, algunos aquí eludidos como el papel de la denominada «clase creativa» en las sociedades urbanas actuales, cuando no su definición misma. Quedan estas otras interpretaciones posibles abiertas a las personas que se aventuren a este gran texto de Ugo Rossi. 